\title{
Descriptive Analysis Of Femur Fracture Patterns, Management And Outcome: Descriptive Observational Study From A Level 1 Trauma Center
}

Syed Imran Ghouri

Hamad Medical Corporation

Mohammad Asim

Hamad General Hospital

Fuad Mustafa

Hamad Medical Corporation

Ahad Kanbar

Hamad Medical Corporation

Mohamed Ellabib

Hamad Medical Corporation

Hisham Al Jogol

Hamad Medical Corporation

Mohammed Muneer

Hamad Medical Corporation

Nuri Abdurraheim

Hamad Medical Corporation

Aterik Pratap Goel

Hamad Medical Corporation

Husham Abdelrahman

Hamad Medical Corporation

Hassan Al-Thani

Hamad Medical Corporation

Ayman El-Menyar ( $\sim$ aymanco65@yahoo.com )

Weill Cornell Medical College in Qatar https://orcid.org/0000-0003-2584-953X

Research article

Keywords: femur fracture, orthopedic trauma, management and outcome

Posted Date: June 4th, 2020

DOI: https://doi.org/10.21203/rs.3.rs-32826/v1 
License: (c) (i) This work is licensed under a Creative Commons Attribution 4.0 International License. Read Full License 


\section{Abstract}

Background We aimed to assess the patterns, associated injuries, management and outcome of traumatic femoral fractures.

Methods This retrospective study was conducted to include all trauma patients with femoral shaft fractures admitted in a level 1 trauma center between January 2012 and December 2015. Data were analyzed and compared according to the time to intramedullary nailing; mechanisms of injury and age groups.

Results A total of 605 cases were analyzed, with mean age of $30.7 \pm 16.2$ years. The majority of fractures were unilateral (96.7\%) and $91 \%$ were closed fractures. Three-fourth of fractures were treated by reamed intramedullary nailing (rIMN); antegrade in $80 \%$. The pyriform fossa nails were used in $71.6 \%$ while trochanteric entry nails was used in $28.4 \%$. Forty five (8.9\%) of fractures were treated with external fixator, 37 (6.1\%) had conservative management. Victims of traffic-related accidents were younger, sustained severe injuries, and more likely to have rIMN and required more blood transfusion. Traffic-related injuries occured more in patients aged 14-30 years whereas; injuries related to fall were significantly higher in patients aged 31-59 years. Thirty-one patients $(7.8 \%)$ had rIMN $<0-6 \mathrm{~h}, 106(25.5 \%)$ had rIMN $<6-12 \mathrm{~h}$ and $267(66.8 \%)$ had rIMN $>12 \mathrm{~h}$. The implant type, duration of surgery, DVT prophylaxis, in-hospital complications and mortality were comparable among the three treatment groups.

Conclusions the frequency of femoral fracture is $11 \%$ mainly in severely injured young males by trafficrelated accidents and falls. Further multicenter studies are needed.

\section{Introduction}

Traumatic femur fracture following road traffic accidents is a significant cause of morbidity with an annual incidence between 1.0 and 2.9 million worldwide [1]. Femur is the most commonly fractured long bone in the body which often necessitates surgical fixation [2]. Femoral shaft fractures have bimodal distribution across age groups with high velocity injuries that are more common among adult males while low energy injuries tend be more common in children and elderly females [3]. The most commonly injured site of femur is the midshaft particularly among adults population following road traffic accidents[4]. These fractures might potentially result in higher rate of short and long-term disabilities which are being measured using disability weights for treated and non-treated patients [5]. It has been shown that the majority of patients with age 35 years and above who sustained moderate injuries have prior indication of generalized osteopenia [6].

Assosciated injuries with femoral shaft fractures are the major cause of morbidity in polytrauma patients [7]. There is an evidence that femoral shaft fractures have frequent assosciation with skeletal injuries (46.4\%) and one-fourth of cases had occult assocaited injuries [8]. Notably, many studies have reported the presence of assosciated injuries such as hemothorax, bowel and head injuries concomitant with femur shaft fracture which dictates the severity of injury [8-10]. Of note, there are certain factors such as 
age, gender, mechanism of injury and magnitude of traumatic impact which might influence the site of femoral fracture $[11,12]$. Moreover, femoral fractures may be assocaited with severe complications such as haemorrhage, pulmonary complications, deep vein thrombosis and wound infection in adult population [13].

There are various treatment options for femur fixation such as conservative management, fixation with screw and plate, intramedullary nailing, open reduction and internal fixation, external fixation and total knee replacement [3]. Diaphyseal femur fractures are preferably treated with intramedullary nailing which helps to attain appropriate bone alignment, quicker bone healing that allows early mobilization and lower rate of complications [14]. An earlier study from our center observed an association between early intramedullary nailing (within $12 \mathrm{~h}$ of injury) with fewer hospital complications and shorter length of hospital stay [15]. Similarly, Harvin et al [13] reported an independently association between early intramedullary nailing (within 24 hours) for femur fixation with lower rate of pulmonary complications. The pattern, presentation and management of femoral fractures are influenced by demographic characterstics, severity and mechanism of injury, and site of fracture. In Qatar, most victims of blunt trauma are young males sustaining proportionately higher injuries to the head, upper and lower extremities with only few articles addressing the femur injuries [16]. Herein, the present study aims to determine the patterns, associated injuries, timing of management and outcome of traumatic femoral fractures in a level 1 trauma center.

\section{Methods}

This retrospective study was conducted to include all trauma patients with femoral shaft fractures admitted in a level 1 trauma center at Hamad General Hospital, Doha, Qatar between January 2012 and December 2015. During the study, 6817 trauma cases were admitted at our referral center which is providing trauma services to the entire population (1,832,903 inhibitants in 2012 and 2,235,355 in 2015) in the state of Qatar. Ethical approval was obtained from the Institutional Review Board (IRB\#16240/16) of the Hamad Medical Corporation before commencing this study and the IRB has granted exempt status for this retrospective study. All trauma patients admitted for the management of femoral fractures were included in the study. Patients with incomplete data, brought in dead, patients who died in the hospital without treatment or transferred to other facilities were excluded. All nails were reamed and inserted in an antegrade or retrograde fashion in the lateral decubitus or supine position. Indications for retrograde nailing were ipsilateral acetabular, pelvis, or femoral neck fractures, polytrauma necessitating multiple simultaneous surgeries. The collected data from the trauma registry database and patients' medical records included demographic characterstics, mechanism of injury, comorbidities, initial vital signs, assocaited injuries, abbreviated injury scores, Injury Severity Score, Glasgow Coma Score, blood transfusion, DVT prophylaxis, pre-operative heparin, pattern of injuries (unilateral or bilateral), type of femur fracture (open/closed), management (conservative or intramedullary nailing), time to intramedullary nailing, reamed, procedure (open/closed), site of entry (piriformis/trochanteric), implant type (antegrade/retrograde nail), in-hospital course, hospital length of stay, complications and outcome. This study follows the STROBE checklist (Suppl table). 


\section{Statistical Analysis}

Data were reported as proportion, mean ( \pm standard deviation), median, and range, when applicable. Patients were categorized into three groups based on the time to intramedullary nailing (Group-1: 0-6 hours; Group-2: 6-12 hours and Group-3: >12 hours). We have also analysed the data according to the mechanism of injury and age groups ( $\leq 13$ years, $14-30$ years, $31-59$ years, and $\geq 60$ years). For each subgroup of patients, the categorical variables were compared using the Pearson chi-square test and oneway ANOVA tests for continuous variables. Yates' corrected chi-square was used for categorical variables, if the expected cell frequencies were below 5. Data analysis was carried out using SPSS version 18 (SPSS Inc., Chicago, Illinois, USA).

\section{Results}

During the 4-year period, 6817 trauma patients were admitted to our center; of which $740(10.9 \%)$ patients presented with femur fracture. One-hundred four cases were excluded because of incomplete information, 18 patients died in the hospital prior to intervention, 10 were transferred to another facility and 3 were brought-in-dead to the hospital. So after excluding 135 patients, 605 patients (9\%) were analyzed which constituted the study cohort (Figure 1). The majority of patients were males $(89.4 \%)$ with a mean age of the cohort $30.7 \pm 16.2$ years. Table 1 shows that the majority of fractures $(n=393,65 \%)$ resulted from road traffic accidents followed by fall from height $(26 \%)$ and fall of heavy objects $(6 \%)$. The frequent comorbidities were hypertension (7\%), diabetes mellitus (6.4\%) and asthma (6.0\%). The mean initial vital signs such as heart rate, body temperature, systolic blood pressure and respiratory rate were unremarkable in the study cohort. The mean injury severity score (ISS) was $14.8 \pm 8.1$. Associated injuries to the chest, head and abdomen were found in $24.1 \%, 16.2 \%$ and $15.9 \%$ cases, respectively. Forty-three percent had concomitant lower extremity fracture requiring internal fixation; $18 \%$ had associated pelvis fracture and $19.8 \%$ sustained spine fracture.

Table 2 shows the management, complications and outcome of femur fracture. Deep vein thrombosis (DVT) prophylaxis was given to $76.5 \%$ and only $7.3 \%$ had received pre-operative heparin. The majority of femur fractures were unilateral (96.7\%) and $91 \%$ were closed fractures. Three-fourth of femur fractures were treated by reamed intramedullary nailing (rIMN), antegrade in $80 \%$ and retrograde in $20 \%$. The pyriform fossa nails $(71.6 \%)$ were used more commonly followed by trochanteric entry nails $(28.4 \%)$. Forty five (8.9\%) of the fractures were treated with external fixator, and $37(6.1 \%)$ had conservative management. Blood transfusion was required in $39.5 \%$ with a median of 4 blood units. Post-treatment, $12.6 \%$ of cases developed wound infection. About $9.7 \%$ were diagnosed with pulmonary complications such as pneumonia (7.3\%), pulmonary embolism (1.2\%) and Acute Respiratory Distress Syndrome (1.2\%). The other complications included sepsis (4.0\%) and acute renal failure secondary to acute tubular necrosis $(2.1 \%)$. The median length of hospital stay was 10 days and ICU stay was 7 days. The overall hospital mortality rate was $2.1 \%$. 
Table 3 analyzed the management, complications and outcome by timing of intramedullary nailing. Patients were divided into three groups : 31 (7.8\%) were in Group I (rIMN < 0-6 h), 106 (25.5\%) were in Group II (rIMN < 6-12 h) and $267(66.8 \%)$ were in Group II (rIMN > 12 h). In Group I and Group II, the common site of entry was Piriformis whereas, trochanteric entry was more evident in Group III patients $(p=0.009)$. The implant type, duration of surgery, DVT prophylaxis, in-hospital complications and mortality were comparable among these three groups.

Table 4 shows the clinical characteristics, management, and outcome of femur fracture based on the mechanisms of injury. In comparison to other groups, victims of traffic-related accidents were younger, sustained severe injuries (mean ISS; $15.8 \pm 8.7 ; p=0.001)$ and frequently had associated tibia $(p=0.006)$ and fibula fractures $(p=0.02)$. Whereas, associated abdominal injuries were observed more in patients injured by fall of heavy object $(p=0.03)$. The rate of rIMN was significantly higher in victims of traffic accidents $(p=0.005)$. Whereas, victims of fall of heavy object were more likely to be treated conservatively. The need for blood transfusion was significantly higher in victims of traffic accidents and fall of heavy objects $(p=0.002)$. There was no significant difference with respect to the time of rIMN, site of entry, implant type, procedure, in-hospital complication and mortality among all the groups.

Table 5 shows predominance of age group 14-30 years (46.4\%) and 31-59 years (36.9\%). Moreover, males patients predominated in the age group 31-59 years as compared to other groups. Traffic related injuries were more in patients aged 14-30 years whereas; injuries related to fall from height and fall of heavy object were significantly higher in patients aged 31-59 years (Figure 2). Young adults aged 14 to 30 years sustained severe injuries with higher injury severity score $(16.2 \pm 8.9 ; p=0.001)$, had frequent spinal injuries $(p=0.004)$ and underwent rIMN $(p=0.001)$ as compared to other groups. Patients aged $\leq 13$ years were frequently managed conservatively. Patients aged 31-59 years were more likely to reveive DVT prophylaxis $(p=0.001)$ and had higher rate of wound infection $(p=0.02)$. The need for blood transfusion $(p=0.001)$ and prolonged hospitalization $(p=0.001)$ were evident among elderly population ( $\geq 60$ years) when compared to other age groups. The study groups did not differ significantly with respect to other associated injuries, in-hospital complications and mortality.

\section{Discussion}

It is imperative to assess the clinico-epidemiological characterstics, mechanisms of injury and pattern of femoral fractures to review the appropriateness of management practices and develop preventive measures. There are several key features of the current analysis. It has been identified that the proportion of traumatic femur fracture cases managed at our centre is $11 \%$ which is in agreement with an earlier study that reported similar rates of femoral fractures treated at a regional trauma centre from South Nigeria [17]. The result of our study showed preponderance of male gender (89.4\%) and young age (mean 30 years) which is in line but with a slightly lower mean age in comparison to an earlier study from Saudi Arabia (33 years) [18]. In contrast, Khan et al [3] reported higher proportion of females (58\%) and advanced age (mean 63 yeras) among distal femoral shaft fractures treated at a tertiary referral hospital in London. An earlier study from Saudia Arabia reported that half of femur fracture victims belongs to 
age group of 16 to $<30$ years followed by 30 to $<60$ years (39.3\%) [18]. The present study also shows predominance of age 14-30 years (46.4\%) and 31-59 years (36.9\%) which is in agreement with Saudia Arabia study and could be due to the sociodemographic similarity between the two countries.

Road traffic accidents $(65 \%)$ remains the most common injury mechanism followed by fall from height in our series. These findings are in agreement with earlier studies which also reported high impact trauma mainly road traffic crashes as the commonest cause of femur fractures [2,17]. Furthermore, traffic related injuries were more evident among young individuals (14-30 years) who represents the most active age group of young individuals usually involved in overspeeding and reckless driving. On the other hand, in our series fall-related injuries predominated in the 31-59 years group which is often related to occupational injuries and domestic fall. In our study group, victims of traffic-related accidents had associated fractures of tibia and fibula and more likely to undergo rIMN. Similarly, predominance of femoral shaft fractures secondary to road traffic accidents among younger males have been reported by an earlier study from Romania [19]. A recent study on management of femoral shaft fractures reported road traffic accidents as the commonest cause and suggested interlocking intramedullary nailing as the modality of choice for candidates requiring operative intervention [20]. In our study, thorax, head and abdomen were the frequently associated injured body regions which is supported by a recent metaanalysis that reported high-energy trauma as the major cause of femur fracture; with concomitant injuries to the chest and head region [21].

In our series, the majority of femur fractures were closed and were frequently unilateral. The pattern of closed femoral fractures is frequently observed due to soft tissue cover of the femur which in contrast with the tibial fractures [8]. Ibeanusi and Chioma [17] reported higher proportion of femoral fractures to be closed (78\%) as compared to open fratures $(22 \%)$ which were more likely to involve diaphyseal femur fracture $(58.1 \%)$ secondary to high impact trauma by road traffic accidents or gunshot injuries. On the other hand , open femur fractures are not uncommon and ranges from 16.5-23\% [22,23]. An external fixator construct could be used to stabilize hemodynamically unstable patients or those with severe open fractures, in accordance with the recommendations of Brumbacks and colleagues for safely performing intramedullary nailing in lower grade open femoral shaft fractures $[24,25]$. Reamed intramedullary nailing is the standard of care treatment in our institution for shaft fractures of long bones particularly the closed method which has been suggested as superior to other procedures, despite the controversy [26-28]. In our series, the median time to stabilize femur fractures by rIMN was within the first 20 hours of admission but early stabilization was observed in $34.3 \%$ of cases as opposed to $51 \%$ reported in an earlier study from our center [21]. The earlier studies have advocated the beneficial effect of early definitive fixation of femur fractures within 24 hours among suitable patients for IMN $[13,29]$. Interestingly, the type of implant, duration of surgery, DVT prophylaxis, and in-hospital complication did not differ significantly based on time to IMN in the present study. This could be due to the fact that we have categorized the time of rIMN as very early, early and delayed surgery but still demonstrate that twothird were treated after 12 hours of admission. 
Antegrade nailing was performed in the majority of our cases with lateral positioning without the use of a fracture table as described by Bishop and colleagues [30]. An earlier study by Wolinsky et al [31] suggested a significant decrease in the operating times with this technique; however, the current study did not compare operating times based on positioning (lateral versus supine). In about one-fourth of fractures, a retrograde nail was inserted in the supine position which is in accordance with the indications described by sanders et al [32]. Surgeons preference in our series was antegrade nails involving entry from pyriform fossa in the majority $(72 \%)$ of cases and the remaining cases had trochanteric entry nails. In contrast to our practice, a systematic review by Kumar et al [33] identified trochanteric entry nailing to be superior to Pyriform fossa nailing to treat femur shaft fractures in adults. The authors also suggested the ease of learning the technique of entry through greater trochanteric tip that resulted in improved functional outcomes; although there is no differece in the rates of union among the two entry sites. Another prospective cohort study on antegrade femoral nailing reported similar higher rate of union, lower complication rates, and comparable functional results of trochanteric insertion as compared to the piriformis fossa nailing [34]. In addition, the authors demonstrated lesser fluoroscopy and operation time with greater trochanter entry in obese patients. Further supporting the notion of trochanteric entry nails, another study on cadavers found lesser structural and iatrogenic injury to the surrounding structures and the gluteal musculature with trochanteric nailings [35]. In our series, open reduction was performed in about one-third of patients and this approach is secondary to difficult closed reduction procedure that has consistently been described as a safe alternative technique [36,37]. In this study, external fixation for the treatment of femoral shaft was primarily done for open fractures. Although, this is not a standard technique to treat femoral shaft fractures but exceptionally can be used to manage open fractures with concomitent complex soft tissue injuries [17].

In this study, about $40 \%$ of the patients required blood transfusion which is markedly lower than the reported incidence in an earlier study [38]. This is attributed to the fact that post-initial resuscitation in polytrauma patient, we meticulously avoid blood transfusions for a hemoglobin level more than $8 \mathrm{mg} / \mathrm{dl}$ [39] among asymptomatic patient who responded well to physiotherapy and ambulation efforts.

The rates of surgical site infection after IMN have been reported to be $11.8 \%$ for combined femur and tibial fractures [40]. Whereas, the overall rate of infection for isolated femur fractures was found to be as low as $0.8 \%$ [41]. Notably, the rate of wound infection in our series was higher and all patients with surgical site infection were managed with local wound care and antibiotics, implant retention and did not require surgical debridement or implant removal. An earlier study analysed the outcome of femoral fractures reported a lower infection rate (5.4\%) as compared to our findings [17].

In our cohort, the rate of pulmonary embolism and ARDS was found to be $1.2 \%$. Similar to our observations, Kim et al [42] reported slightly higher frequency of pulmonary embolism (2.2\%) which developed soon post-trauma. Bosse et al [43] reviewed femur fractures magement at two different settings, one center has used rIMN and the other mainly used plates to treat femoral fractures. The authors suggested that rIMN of femoral fractures did not increase the risk of pulmonary complications and there was no significant difference between the two cohorts with respect to the incidence of 
pulmonary complication and mortality. Other studies have also recommended that hemodynamically stable patients with pulmonary injuries and femoral fracture can be successfully treated with rIMN $[44,45]$. Moreover, a recent meta-analysis identified that early IMN has lower risk of pulmonary complications such as ARDS, and pneumonia as compared to delayed IMN fixation [21]. Therefore, in polytrauma patients the reported pulmonary complications might be associated with thorax trauma rather than the IMN [46].

There are certain limitations to this study owing to the retrospective study design and data retrival from registry database, having some variables with incomplete information. Moreover, the registry databse did not capture the duration and details of the surgical procedures which was retrieved from the patient's medical record. We lack details of the force and location of impact and use of protection measure while driving or at workplace.

Third, the lack of information regarding the exact site of femur, fracture geometry (transverse or short oblique type or comminuted), fracture classification and risk factors for fracture. Finally, this study did not address the functional outcome as radiological union (nonunioun, malunion, extended delayed union) and clinical follow-up details about physical therapy, early mobilization, and counseling.

In conclusion, the frequency of femoral fracture is $11 \%$ mainly in severely injured young males by trafficrelated accidents and fall from height. The femoral fracture represents a spectrum of injury characteristics from simple isolated injuries requiring a simple intramedullary nail to polytrauma patient with associated injuries that require multidisciplinary treatment approach. We believe that clinicoepidemiological study may help the surgeons to understand pattern of fractures, management and complications to improve patient's outcomes. Our findings may help healthcare policy prioritization, resource allocation planning and implementation of best practices. Further studies are needed to focus on type and side of fracture, exact location and prognoses of femur fracture patients.

\section{Abbreviations}

ISS: injury severity score

rIMN : reamed intramedullary nailing

\section{Declarations}

Ethics approval and consent to participate: This observational study has received an expedited review and was approved by the Institutional Review Board (HMC IRB\# 16240/16)

Consent for publication: was approved by the Institutional Review Board

Availability of data and material: not applicable

Competing interests: The authors declare no conflict of interest. 
Funding: none

Authors' contributions: all authors have a substantial contribution in the study design, data interpretation and writing and reviewing the manuscript

Acknowledgment: The authors thank all the staff of the trauma registry database at the trauma surgery section. All authors have a substantial contribution in the study design, data entry, and interpretation as well as the manuscript writing and review.

\section{References}

1. Agarwal-Harding KJ, Meara JG, Greenberg SL, et al. Estimating the global incidence of femoral fracture from road traffic collisions: a literature review. J Bone Joint Surg Am. 2015;97(6):e31.doi: 10.2106/JBJS.N.00314.2. Anyaehie UE, Ejimofor OC, Akpuaka FC, et al. Pattern of femoral fractures and associated injuries in a Nigerian tertiary trauma centre. Niger J Clin Pract 2015;18:462-63. Khan AM, Tang QO, Spicer D. The Epidemiology of Adult Distal Femoral Shaft Fractures in a Central London Major Trauma Centre Over Five Years. Open Orthop J. 2017 Nov 13;11:1277-1291

2. Salminen ST, Pihlajamäki HK, Avikainen VJ, et al. Population based epidemiologic and morphologic study of femoral shaft fractures. Clin Orthop Relat Res. 2000;(372):241-9.

3. Matityahu A, Elliott I, Marmor M, et al. Time intervals in the treatment of fractured femurs as indicators of the quality of trauma systems. Bull World Health Organ. 2014;92:40-50.

4. Coon MS, Best BJ. Distal Femur Fractures. [Updated 2019 Nov 17]. In: StatPearls [Internet]. Treasure Island (FL): StatPearls Publishing; 2020 Jan-. Available from: https://www.ncbi.nlm.nih.gov/books/NBK551675/

5. O'Brien PJ. Fracture fixation in patients having multiple injuries. Can J Surg. $2003 ; 46(2): 124-8$.

6. Rodriguez-Merchan EC, Moraleda L, Gomez-Cardero P. Injuries associated with femoral shaft fractures with special emphasis on occult injuries. Arch Bone Jt Surg. 2013 ;1:59-63.

7. Adili A, Bhandari M, Lachowski RJ, et al. Organ injuries associated with femoral fractures: implications for severity of injury in motor vehicle collisions. J Trauma. 1999;46:386-91.

8. Brumback RJ, Virkus WW. Intramedullary nailing of the femur: reamed versus nonreamed. J Am Acad Orthop Surg. 2000;8:83-90.

9. Wu SC, Rau CS, Kuo SCH, et al. The influence of ageing on the incidence and site of trauma femoral fractures: a cross-sectional analysis. BMC Musculoskelet Disord. 2019;20:413. doi: 10.1186/s12891019-2803-x.

10. Chang MW, Liu HT, Huang CY, et al. Location of Femoral Fractures in Patients with Different Weight Classes in Fall and Motorcycle Accidents: A Retrospective Cross-Sectional Analysis. Int J Environ Res Public Health. 2018;15(6). pii: E1082. doi: 10.3390/ijerph15061082.

11. Harvin JA, Harvin WH, Camp E, et al. Early femur fracture fixation is associated with a reduction in pulmonary complications and hospital charges: a decade of experience with 1,376 diaphyseal femur 
fractures. J Trauma Acute Care Surg. 2012;73:1442-8; discussion 1448-9. doi: 10.1097/TA.0b013e3182782696.

12. Medda S, Halvorson J. Diaphyseal Femur Fracture. [Updated 2019 Dec 12]. In: StatPearls [Internet]. Treasure Island (FL): StatPearls Publishing; 2020 Jan-. Available from: https://www.ncbi.nlm.nih.gov/books/NBK493169/

13. Alobaidi AS, Al-Hassani A, El-Menyar A, et al. Early and late intramedullary nailing of femur fracture: A single center experience. Int J Crit Illn Inj Sci. 2016;6:143-147.

14. Asim M, El-Menyar A, Al-Thani $\mathrm{H}$, et al. Blunt traumatic injury in the Arab Middle Eastern populations. J Emerg Trauma Shock. 2014;7:88-96. doi: 10.4103/0974-2700.130878.

15. Ibeanusi SE, Chioma J. Pattern and Outcome of Femoral Fractures Treated in a Regional Trauma Centre in South South, Nigeria. Int Arch Orthop Surg 2019, 2:006

16. Sonbol AM, Almulla AA, Hetaimish BM, et al. Prevalence of femoral shaft fracture and associated injuries among adults after road traffic accidents in a Saudi Arabian trauma center. J Musculoskelet Surg Res 2018;2:62-5.

17. Kouris G, Hostiuc S, Negoi I. Femoral fractures in road traffic accidents. Rom J Leg Med 2012;20: 279-282. DOI: $10.4323 /$ rjlm.2012.279

18. Ugezu Al, Nze IN, Ihegihu CC, et al. Management of Femoral Shaft Fractures in a Tertiary Centre, South East Nigeria. Afri Medic J 2018; 6: 27-34.

19. El-Menyar A, Muneer M, Samson D, et al. Early versus late intramedullary nailing for traumatic femur fracture management: meta-analysis. J Orthop Surg Res. 2018;13(1):160. doi: 10.1186/s13018-0180856-4.

20. Brumback RJ, Uwagie-Ero S, Lakatos RP, et al. Intramedullary nailing of femoral shaft fractures. Part II: Fracture-healing with static interlocking fixation. J Bone Joint Surg 1988;70A:1453-62.

21. Winquist RA, Hansen ST, Jr, Clawson DK. Closed intramedullary nailing of femoral fractures: a report of five hundred and twenty cases. J Bone Joint Surg1984;66A:529-39.

22. Brumback RJ, Ellison PS Jr, Poka A, et al. Intramedullary nailing of open fractures of the femoral shaft. J Bone Joint Surg Am. 1989 Oct;71(9):1324-31.

23. Pape HC, Giannoudis $P$, Krettek $C$. The timing of fracture treatment in polytrauma patients: relevance of damage control orthopedic surgery. Am J Surg. $2002 ; 183: 622-9$.

24. Li AB, Zhang WJ, Guo WJ, et al. Reamed versus unreamed intramedullary nailing for the treatment of femoral fractures: A meta-analysis of prospective randomized controlled trials. Medicine (Baltimore). 2016;95(29):e4248.

25. Canadian Orthopaedic Trauma Society. Reamed versus unreamed intramedullary nailing of the femur: comparison of the rate of ARDS in multiple injured patients. J Orthop Trauma. 2006;20(6):384-387.

26. Giannoudis PV, Tzioupis C, Pape HC. Fat embolism: the reaming controversy. Injury. 2006;37:S50-8. 
27. Charash WE, Fabian TC, Croce MA. Delayed surgical fixation of femur fractures is a risk factor for pulmonary failure independent of thoracic trauma. J Trauma 1997;37:667-672.

28. Bishop JA, Rodriguez EK. Closed intramedullary nailing of the femur in the lateral decubitus position. J Trauma. 2010;68:231-5. doi:10.1097/TA.0b013e3181c488d8.

29. Wolinsky PR, McCarty EC, Shyr Y, et al. Length of operative procedures: reamed femoral intramedullary nailing performed with and without a fracture table. J Orthop Trauma. 1998;12:48595.

30. Sanders R, Koval KJ, DiPasquale T, et al. Retrograde reamed femoral nailing. J Orthop Trauma. 1993;7(4):293-302.

31. Kumar P, Neradi D, Kansal R, et al. Greater trochanteric versus piriformis fossa entry nails for femur shaft fractures: Resolving the controversy. Injury. 2019;50(10):1715-1724. doi: 10.1016/j.injury.2019.07.011.

32. Ricci WM, Schwappach J, Tucker M, et al. Trochanteric versus piriformis entry portal for the treatment of femoral shaft fractures. J Orthop Trauma. 2006;20:663-7.

33. Ansari Moein CM, Verhofstad MH, Bleys RL, et al. Soft tissue injury related to choice of entry point in antegrade femoral nailing: piriform fossa or greater trochanter tip. Injury. 2005;36:1337-42.

34. Tahririan MA, Andalib A. Is there a place for open intramedullary nailing in femoral shaft fractures? Adv Biomed Res. 2014;3:157. doi: 10.4103/2277-9175.137870.

37. Burç H, Atay T, Demirci D, et al. The Intramedullary Nailing of Adult Femoral Shaft Fracture by the Way of Open Reduction is a Disadvantage or Not? Indian J Surg. 2015 Dec;77(Suppl 2):583-8.doi: 10.1007/s12262-013-0931-3.

38. Lieurance R, Benjamin JB, Rappaport WD. Blood loss and transfusion in patients with isolated femur fractures. J Orthop Trauma. 1992;6:175-9.

39. Ponnusamy KE, Kim TJ, Khanuja HS. Perioperative blood transfusions in orthopaedic surgery. J Bone Joint Surg Am. 2014;96:1836-44. doi: 10.2106/JBJS.N.00128.

40. Oliveira PR, Leonhardt MC, Carvalho VC, et al. Incidence and risk factors associated with infection after intramedullary nailing of femoral and tibial diaphyseal fractures: Prospective study. Injury. 2018;49:1905-1911. doi:10.1016/j.injury.2018.07.024

41. Young S, Lie SA, Hallan G, et al. Risk factors for infection after 46,113 intramedullary nail operations in low- and middle-income countries. World J Surg. 2013;37(2):349-355. doi:10.1007/s00268-012$1817-4$

42. Kim YJ, Choi DH, Ahn S, et al. Timing of pulmonary embolisms in femur fracture patients: Incidence and outcomes. J Trauma Acute Care Surg.2016 Jun;80(6):952-6. doi: 10.1097/TA.0000000000001014.

43. Bosse MJ, MacKenzie EJ, Riemer BL, et al. Adult respiratory distress syndrome, pneumonia, and mortality following thoracic injury and a femoral fracture treated either with intramedullary nailing with reaming or with a plate. A comparative study. J Bone Joint Surg Am. 1997;79:799-809. 
44. van der Made WJ, Smit EJ, van Luyt PA, et al. Intramedullary femoral osteosynthesis: an additional cause of ARDS in multiply injured patients? Injury 1996;27:391-3.

45. Bone LB, Anders MJ, Rohrbacher BJ. Treatment of femoral fractures in the multiply injured patient with thoracic injury. Clin Orthop Relat Res. 1998;(347):57-61.

46. Nahm NJ, Como JJ, Wilber JH, Vallier HA. Early appropriate care: definitive stabilization of femoral fractures within 24 hours of injury is safe in most patients with multiple injuries. J Trauma. 2011;71:175-85.

\section{Tables}

\begin{tabular}{|c|c|c|c|}
\hline Variables & Value & Variables & Value \\
\hline Age (mean $\pm \mathrm{SD})$ & $30.7 \pm 16.2$ & Associated injuries & \\
\hline Males & $541(89.4 \%)$ & Tibia & $106(17.5 \%)$ \\
\hline Qatari & $153(25.3 \%)$ & Fibula & $68(11.2 \%)$ \\
\hline Mechanism of Injury & & Ankle & $46(7.6 \%)$ \\
\hline MVC & $264(43.6 \%)$ & Knee & $39(6.4 \%)$ \\
\hline Pedestrian & $81(13.4 \%)$ & Pelvis & $109(18.0 \%)$ \\
\hline Motor cycle/bike crash & $32(5.3 \%)$ & Head & $98(16.2 \%)$ \\
\hline ATV & $16(2.6 \%)$ & Chest & $146(24.1 \%)$ \\
\hline Fall from height & $157(26.0 \%)$ & Abdomen & $96(15.9 \%)$ \\
\hline Fall of heavy object & $36(6.0 \%)$ & Spine & $120(19.8 \%)$ \\
\hline Others & $19(3.1 \%)$ & Abbreviated injury scores & \\
\hline Co-morbidities & & Head AIS & $3.7 \pm 1.4$ \\
\hline Hypertension & $42(6.9 \%)$ & Chest AIS & $2.7 \pm 0.9$ \\
\hline Diabetes mellitus & $39(6.4 \%)$ & Abdominal AIS & $2.7 \pm 1.4$ \\
\hline Asthma & $36(6.0 \%)$ & Spine AIS & $2.1 \pm 0.4$ \\
\hline Coronary Artery Disease & $14(2.3 \%)$ & Lower extremity AIS & $3.0 \pm 0.04$ \\
\hline Initial heart rate & $96.3 \pm 21.4$ & Pelvis AIS & $2.2 \pm 0.7$ \\
\hline Initial SBP & $125.9 \pm 20.4$ & Hemoglobin $(n=509)$ & $13.0 \pm 2.2$ \\
\hline Temperature & $36.8 \pm 0.5$ & WBC $(n=488)$ & $15.2 \pm 6.4$ \\
\hline Respiratory rate & $20.3 \pm 5.9$ & Neutrophil $(n=255)$ & $14.7 \pm 13.8$ \\
\hline Initial GCS & $14.1 \pm 3.02$ & Platelets $(n=499)$ & $259.5 \pm 92.3$ \\
\hline \multirow[t]{3}{*}{ Injury Severity Score } & $14.8 \pm 8.1$ & INR $(n=466)$ & $1.07 \pm 0.14$ \\
\hline & & X-ray & $603(99.7 \%)$ \\
\hline & & CT $\operatorname{scan}(n=430)$ & $243(56.5 \%)$ \\
\hline
\end{tabular}




\begin{tabular}{|c|c|}
\hline Variables & Value \\
\hline DVT prophylaxis (n=489) & $374(76.5 \%)$ \\
\hline Pre-operative heparin $(n=410)$ & $30(7.3 \%)$ \\
\hline Unilateral femur fracture & $584(96.7 \%)$ \\
\hline Bilateral femur fracture & $20(3.3 \%)$ \\
\hline \multicolumn{2}{|l|}{ Type of Femur Fracture } \\
\hline Close fracture & $551(91.1 \%)$ \\
\hline Open fracture & $54(8.9 \%)$ \\
\hline Reamed intramedullary nailing & $453(74.9 \%)$ \\
\hline Time to IMN (hours) $(n=400)$ & $20(1-4382)$ \\
\hline Early ( $\leq 12$ h) & $137(34.3 \%)$ \\
\hline Late $(>12 \mathrm{~h})$ & $267(66.8 \%)$ \\
\hline External fixation & $45(8.9 \%)$ \\
\hline Conservative management & $37(6.1 \%)$ \\
\hline \multicolumn{2}{|l|}{ Implant type $(n=408)$} \\
\hline Antegrade nail & $327(80.1 \%)$ \\
\hline Retrograde nail & $81(19.9 \%)$ \\
\hline \multicolumn{2}{|l|}{ Site of entry $(n=342)$} \\
\hline Piriformis & $245(71.6 \%)$ \\
\hline Trochanteric & $97(28.4 \%)$ \\
\hline \multicolumn{2}{|l|}{ Procedure $(n=439)$} \\
\hline Open & $145(33.0 \%)$ \\
\hline Closed & $294(67.0 \%)$ \\
\hline Duration of Surgery (hours) & $2.6 \pm 1.7$ \\
\hline Locking & $453(100 \%)$ \\
\hline Cement & $8(2.1 \%)$ \\
\hline Number of procedures $(n=423)$ & $1(1-7)$ \\
\hline Bleeding on admission $(n=432)$ & $38(8.8 \%)$ \\
\hline Wound Infection ( $n=461)$ & $58(12.6 \%)$ \\
\hline Blood transfusion & $239(39.5 \%)$ \\
\hline Blood units transfused & $4(1-51)$ \\
\hline \multicolumn{2}{|l|}{ Complications } \\
\hline Pneumonia & $44(7.3 \%)$ \\
\hline Pulmonary Embolism & $7(1.2 \%)$ \\
\hline Acute Respiratory Distress Syndrome & $7(1.2 \%)$ \\
\hline Sepsis & $24(4.0 \%)$ \\
\hline Acute renal failure & $13(2.1 \%)$ \\
\hline Hospital length of stay & $10(1-157)$ \\
\hline ICU stay & $7(1-88)$ \\
\hline Mortality & $13(2.1 \%)$ \\
\hline
\end{tabular}




\begin{tabular}{|c|c|c|c|c|}
\hline & \multicolumn{3}{|c|}{ Time to intramedullary nailing* } & \multirow[t]{2}{*}{$P$ value } \\
\hline & $0-6$ hours $(n=31 ; 7.8 \%)$ & $6-12$ hours $(n=106 ; 25.5 \%)$ & $>12$ hours $(n=267 ; 66.8 \%)$ & \\
\hline \multicolumn{5}{|l|}{ Site of entry $(n=301)$} \\
\hline Piriformis & $23(82.1 \%)$ & $70(82.4 \%)$ & $124(66.0 \%)$ & \multirow[t]{2}{*}{0.009 for all } \\
\hline Trochanteric & $5(17.9 \%)$ & $15(17.6 \%)$ & $64(34.0 \%)$ & \\
\hline \multicolumn{5}{|l|}{ Implant type $(n=364)$} \\
\hline Antegrade nail & $26(96.3 \%)$ & $76(77.6 \%)$ & $186(77.8 \%)$ & \multirow[t]{2}{*}{0.07 for all } \\
\hline Retrograde nail & $1(3.7 \%)$ & $22(22.4 \%)$ & $53(22.2 \%)$ & \\
\hline Duration of Surgery (hours) & $3.2 \pm 1.6$ & $2.7 \pm 1.6$ & $2.6 \pm 1.5$ & 0.17 \\
\hline Wound Infection (n=312) & $3(12.5 \%)$ & $12(13.3 \%)$ & $27(13.6 \%)$ & 0.97 \\
\hline DVT prophylaxis $(n=320)$ & $19(79.2 \%)$ & $67(79.8 \%)$ & $159(75.0 \%)$ & 0.65 \\
\hline Sepsis & $2(6.5 \%)$ & $3(2.9 \%)$ & $9(3.4 \%)$ & 0.91 \\
\hline Pulmonary Embolism & $0(0.0 \%)$ & $0(0.0 \%)$ & $6(2.2 \%)$ & 0.52 \\
\hline Acute Respiratory Distress Syndrome & $1(3.2 \%)$ & $1(1.0 \%)$ & $3(1.1 \%)$ & 0.96 \\
\hline Pneumonia & $2(6.5 \%)$ & $4(3.9 \%)$ & $21(7.9 \%)$ & 0.51 \\
\hline Mortality & $0(0.0 \%)$ & $1(1.0 \%)$ & $4(1.5 \%)$ & 0.96 \\
\hline
\end{tabular}




\begin{tabular}{|c|c|c|c|c|c|}
\hline & $\begin{array}{l}\text { Traffic-related accidents } \\
(\mathrm{n}=393)\end{array}$ & $\begin{array}{l}\text { Fall from height } \\
(n=157)\end{array}$ & $\begin{array}{l}\text { Fall of heavy object } \\
(n=36)\end{array}$ & $\begin{array}{l}\text { Others } \\
(n=19)\end{array}$ & $P$ value \\
\hline Age (mean $\pm S D)$ & $27.8 \pm 12.7$ & $37.9 \pm 21.6$ & $31.7 \pm 13.9$ & $26.9 \pm 12.3$ & 0.001 \\
\hline Males & $359(91.3 \%)$ & $132(84.1 \%)$ & $34(94.4 \%)$ & $16(84.2 \%)$ & 0.05 \\
\hline Qatari & $120(30.5 \%)$ & $25(15.9 \%)$ & $3(8.3 \%)$ & $5(26.3 \%)$ & 0.001 \\
\hline Injury Severity Score & $15.8 \pm 8.7$ & $12.9 \pm 6.3$ & $14.1 \pm 6.5$ & $10.9 \pm 3.8$ & 0.001 \\
\hline ISS $>15$ & $138(35.1 \%)$ & $39(24.8 \%)$ & $11(30.6 \%)$ & $2(10.5 \%)$ & 0.02 \\
\hline \multicolumn{6}{|l|}{ Associated injuries } \\
\hline Tibia & $83(21.1 \%)$ & $14(8.9 \%)$ & $7(19.4 \%)$ & $2(10.5 \%)$ & 0.006 \\
\hline Fibula & $55(14.0 \%)$ & $11(7.0 \%)$ & $1(2.8 \%)$ & $1(5.3 \%)$ & 0.02 \\
\hline Ankle & $31(7.9 \%)$ & $9(5.7 \%)$ & $3(8.3 \%)$ & $3(15.8 \%)$ & 0.44 \\
\hline Knee & $29(7.4 \%)$ & $8(5.1 \%)$ & $1(2.8 \%)$ & $1(5.3 \%)$ & 0.59 \\
\hline Pelvis & $72(18.3 \%)$ & $23(14.6 \%)$ & $10(27.8 \%)$ & $4(21.1 \%)$ & 0.29 \\
\hline Head & $70(17.8 \%)$ & $23(14.6 \%)$ & $3(8.3 \%)$ & $2(10.5 \%)$ & 0.37 \\
\hline Chest & $99(25.2 \%)$ & $33(21.0 \%)$ & $10(27.8 \%)$ & $4(21.1 \%)$ & 0.69 \\
\hline Abdomen & $70(17.8 \%)$ & $14(8.9 \%)$ & $7(19.4 \%)$ & $5(26.3 \%)$ & 0.03 \\
\hline Spine & $80(20.4 \%)$ & $26(16.6 \%)$ & $10(27.8 \%)$ & $4(21.1 \%)$ & 0.46 \\
\hline \multicolumn{6}{|l|}{ Management } \\
\hline Reamed IMN & 307 (78.1\%) & $102(65.0 \%)$ & $28(77.8 \%)$ & $16(84.2 \%)$ & \multirow{3}{*}{$\begin{array}{l}0.005 \text { for } \\
\text { all }\end{array}$} \\
\hline Conservative & $16(4.1 \%)$ & $15(9.6 \%)$ & $5(13.9 \%)$ & $1(5.3 \%)$ & \\
\hline Other procedures & $70(17.8 \%)$ & $40(25.5 \%)$ & $3(8.3 \%)$ & $2(10.5 \%)$ & \\
\hline \multicolumn{6}{|l|}{ Time to IMN (hours) } \\
\hline Early (<12 h) & $76(28.6 \%)$ & $23(24.7 \%)$ & $8(30.8 \%)$ & $4(26.7 \%)$ & \multirow[t]{2}{*}{0.88} \\
\hline Late $(\geq 12 \mathrm{~h})$ & $190(71.4 \%)$ & $70(75.3 \%)$ & $18(69.2 \%)$ & $11(73.3 \%)$ & \\
\hline \multicolumn{6}{|l|}{ Site of entry } \\
\hline Piriformis & $166(72.2 \%)$ & $53(67.1 \%)$ & $16(76.2 \%)$ & $10(83.3 \%)$ & \multirow[t]{2}{*}{0.60} \\
\hline Trochanteric & $64(27.8 \%)$ & $26(32.9 \%)$ & $5(23.8 \%)$ & $2(16.7 \%)$ & \\
\hline \multicolumn{6}{|l|}{ Implant type } \\
\hline Antegrade nail & $215(77.6 \%)$ & $79(84.9 \%)$ & $21(84.0 \%)$ & $12(92.3 \%)$ & \multirow[t]{2}{*}{0.27} \\
\hline Retrograde nail & $62(22.4 \%)$ & $14(15.1 \%)$ & $4(16.0 \%)$ & $1(7.7 \%)$ & \\
\hline \multicolumn{6}{|l|}{ Procedure } \\
\hline Open & $196(66.4 \%)$ & $70(69.3 \%)$ & $18(66.7 \%)$ & $10(62.5 \%)$ & \multirow[t]{2}{*}{0.93} \\
\hline Closed & $99(33.6 \%)$ & $31(30.7 \%)$ & $9(33.3 \%)$ & $6(37.5 \%)$ & \\
\hline Wound Infection & $46(15.1 \%)$ & $8(6.7 \%)$ & $2(8.3 \%)$ & $2(14.3 \%)$ & 0.11 \\
\hline DVT prophylaxis & 249 (78.5\%) & $95(72.5 \%)$ & $21(72.4 \%)$ & $9(75.0 \%)$ & 0.53 \\
\hline Blood transfusion & $172(43.8 \%)$ & $49(31.2 \%)$ & $16(44.4 \%)$ & $2(10.5 \%)$ & 0.002 \\
\hline $\begin{array}{l}\text { Blood units } \\
\text { transfused }\end{array}$ & $4(1-51)$ & $2(1-22)$ & $2(1-16)$ & $11(3-19)$ & 0.009 \\
\hline Sepsis & $19(4.8 \%)$ & $3(1.9 \%)$ & $2(5.6 \%)$ & $0(0.0 \%)$ & 0.31 \\
\hline Pulmonary Embolism & $3(0.8 \%)$ & $4(2.5 \%)$ & $0(0.0 \%)$ & $0(0.0 \%)$ & 0.28 \\
\hline ARDS & $6(1.5 \%)$ & $1(0.6 \%)$ & $0(0.0 \%)$ & $0(0.0 \%)$ & 0.68 \\
\hline Pneumonia & $35(8.9 \%)$ & $4(2.5 \%)$ & $3(8.3 \%)$ & $2(10.5 \%)$ & 0.06 \\
\hline $\begin{array}{l}\text { Hospital length of } \\
\text { stay }\end{array}$ & $10(1-157)$ & $9(1-117)$ & $11(3-104)$ & $7(3-49)$ & 0.07 \\
\hline Mortality & $12(3.1 \%)$ & $1(0.6 \%)$ & $0(0.0 \%)$ & $0(0.0 \%)$ & 0.21 \\
\hline
\end{tabular}




\begin{tabular}{|c|c|c|c|c|c|}
\hline & $\begin{array}{l}\leq 13 \text { years } \\
(n=63 ; 10.5 \%)\end{array}$ & $14-30$ years $(n=279 ; 46.4 \%)$ & $31-59$ years $(n=222 ; 36.9 \%)$ & $\geq 60$ years $(n=37 ; 6.2 \%)$ & $P$ value \\
\hline Males & $50(79.4 \%)$ & $256(91.8 \%)$ & $211(95.0 \%)$ & $20(54.1 \%)$ & 0.001 \\
\hline Qatari & $25(39.7 \%)$ & $92(33.0 \%)$ & $19(8.6 \%)$ & $17(45.9 \%)$ & 0.001 \\
\hline Injury Severity Score & $12.2 \pm 6.1$ & $16.2 \pm 8.9$ & $14.2 \pm 7.2$ & $12.8 \pm 7.7$ & 0.001 \\
\hline ISS $>15$ & $10(15.9 \%)$ & $104(37.3 \%)$ & $66(29.7 \%)$ & $9(24.3 \%)$ & 0.005 \\
\hline \multicolumn{6}{|l|}{ Associated injuries } \\
\hline Tibia & $5(7.9 \%)$ & $48(17.2 \%)$ & $47(21.2 \%)$ & $5(13.5 \%)$ & 0.09 \\
\hline Fibula & $4(6.3 \%)$ & $28(10.0 \%)$ & $32(14.4 \%)$ & $3(8.1 \%)$ & 0.20 \\
\hline Ankle & $3(4.8 \%)$ & $22(7.9 \%)$ & $19(8.6 \%)$ & $1(2.7 \%)$ & 0.50 \\
\hline Knee & $5(7.9 \%)$ & $17(6.1 \%)$ & $15(6.8 \%)$ & $2(5.4 \%)$ & 0.94 \\
\hline Pelvis & $10(15.9 \%)$ & $55(19.7 \%)$ & $38(17.1 \%)$ & $3(8.1 \%)$ & 0.34 \\
\hline Head & $6(9.5 \%)$ & $49(17.6 \%)$ & $38(17.1 \%)$ & $3(8.1 \%)$ & 0.22 \\
\hline Chest & $11(17.5 \%)$ & $73(26.2 \%)$ & $57(25.7 \%)$ & $4(10.8 \%)$ & 0.11 \\
\hline Abdomen & $10(15.9 \%)$ & $53(19.30 \%)$ & $31(14.0 \%)$ & $1(2.7 \%)$ & 0.05 \\
\hline Spine & $4(6.3 \%)$ & $66(23.7 \%)$ & $46(20.7 \%)$ & $3(8.1 \%)$ & 0.004 \\
\hline \multicolumn{6}{|l|}{ Management } \\
\hline Reamed IMN & $37(58.7 \%)$ & $234(83.9 \%)$ & $161(72.5 \%)$ & $18(48.6 \%)$ & \multirow[t]{3}{*}{0.001 for all } \\
\hline Conservative & $17(27.0 \%)$ & $7(2.5 \%)$ & $10(4.5 \%)$ & $3(8.1 \%)$ & \\
\hline Other procedures & $9(14.3 \%)$ & $38(13.6 \%)$ & $51(23.0 \%)$ & $16(43.2 \%)$ & \\
\hline \multicolumn{6}{|l|}{ Time to IMN (hours) } \\
\hline Early $(<12$ h) & $8(24.2 \%)$ & $55(26.7 \%)$ & $44(30.6 \%)$ & $4(25.0 \%)$ & \multirow[t]{2}{*}{0.81 for all } \\
\hline Late $(\geq 12 \mathrm{~h})$ & $25(75.8 \%)$ & $151(73.3 \%)$ & $100(69.4 \%)$ & $12(75.0 \%)$ & \\
\hline \multicolumn{6}{|l|}{ Site of entry } \\
\hline Piriformis & $16(57.1 \%)$ & $135(75.4 \%)$ & $87(71.3 \%)$ & $5(50.0 \%)$ & \multirow[t]{2}{*}{0.09 for all } \\
\hline Trochanteric & $12(42.9 \%)$ & $44(24.6 \%)$ & $35(28.7 \%)$ & $5(50.0 \%)$ & \\
\hline \multicolumn{6}{|l|}{ Implant type } \\
\hline Antegrade nail & $22(64.7 \%)$ & $176(83.0 \%)$ & $113(77.9 \%)$ & $14(93.3 \%)$ & \multirow[t]{2}{*}{0.04 for all } \\
\hline Retrograde nail & $12(35.3 \%)$ & $36(17.0 \%)$ & $32(22.1 \%)$ & $1(6.7 \%)$ & \\
\hline Wound Infection & $2(4.3 \%)$ & $26(12.6 \%)$ & $30(16.8 \%)$ & $0(0.0 \%)$ & 0.02 \\
\hline DVT prophylaxis & $14(28.0 \%)$ & $181(80.8 \%)$ & $154(84.2 \%)$ & $22(75.9 \%)$ & 0.001 \\
\hline Blood transfusion & $7(11.1 \%)$ & $122(43.7 \%)$ & $86(38.7 \%)$ & $22(59.5 \%)$ & 0.001 \\
\hline Blood units transfused & $2(1-10)$ & $4(1-51)$ & $4(1-24)$ & $3(1-8)$ & 0.03 \\
\hline Sepsis & $1(1.6 \%)$ & $12(4.3 \%)$ & $8(3.6 \%)$ & $3(8.1 \%)$ & 0.43 \\
\hline Pulmonary Embolism & $2(3.2 \%)$ & $3(1.1 \%)$ & $1(0.5 \%)$ & $1(2.7 \%)$ & 0.26 \\
\hline ARDS & $0(0.0 \%)$ & $4(1.4 \%)$ & $3(1.4 \%)$ & $0(0.0 \%)$ & 0.70 \\
\hline Pneumonia & $3(4.8 \%)$ & $21(7.5 \%)$ & $19(8.6 \%)$ & $1(2.7 \%)$ & 0.51 \\
\hline Hospital length of stay & $6(1-43)$ & $10(1-157)$ & $10(1-123)$ & $15(4-115)$ & 0.001 \\
\hline Mortality* & $0(0.0 \%)$ & $7(2.5 \%)$ & $3(1.4 \%)$ & $1(2.7 \%)$ & 0.50 \\
\hline
\end{tabular}

\section{Figures}




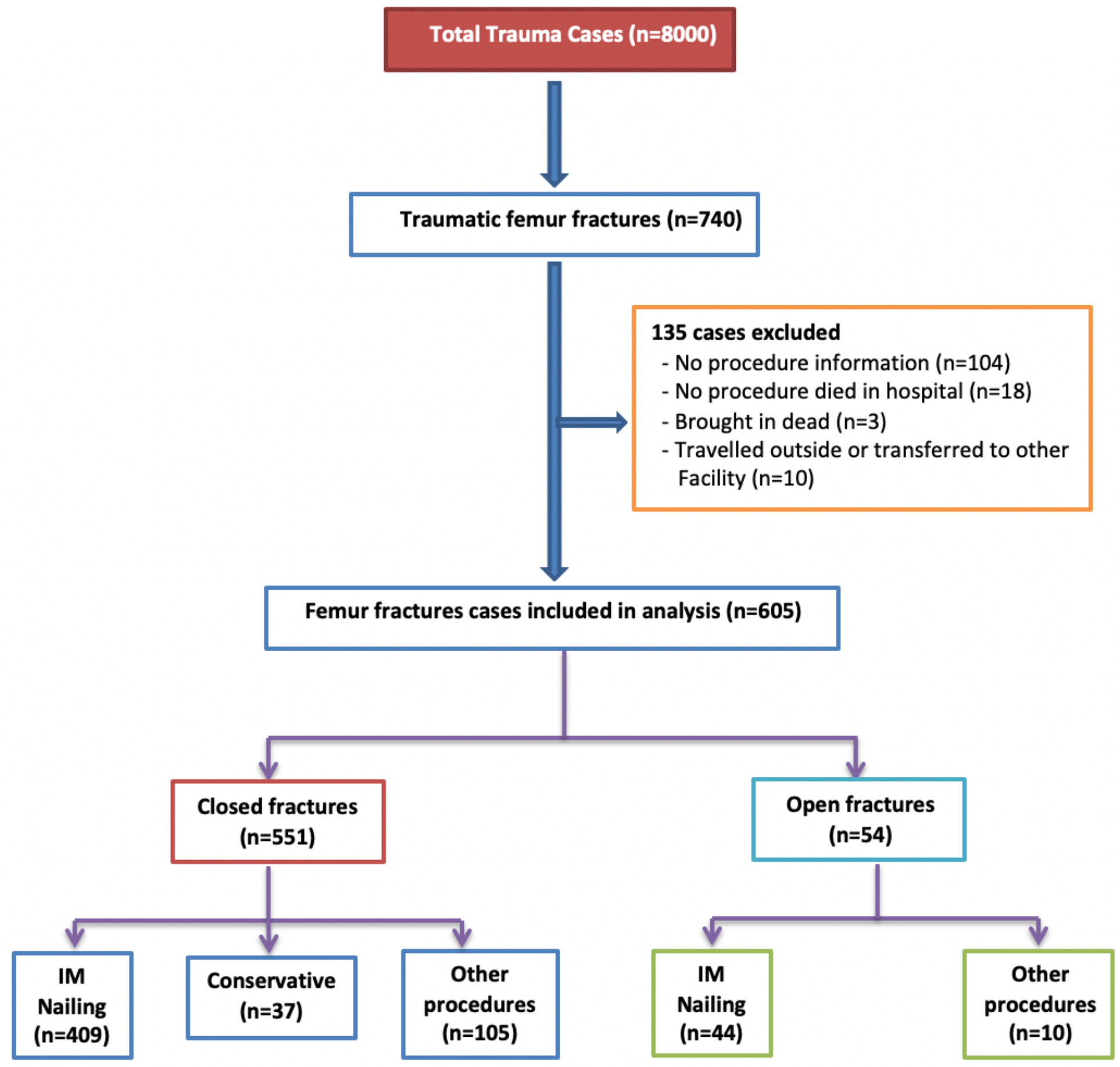

Figure 1

Study design 


\section{Mechanism of injury by age}

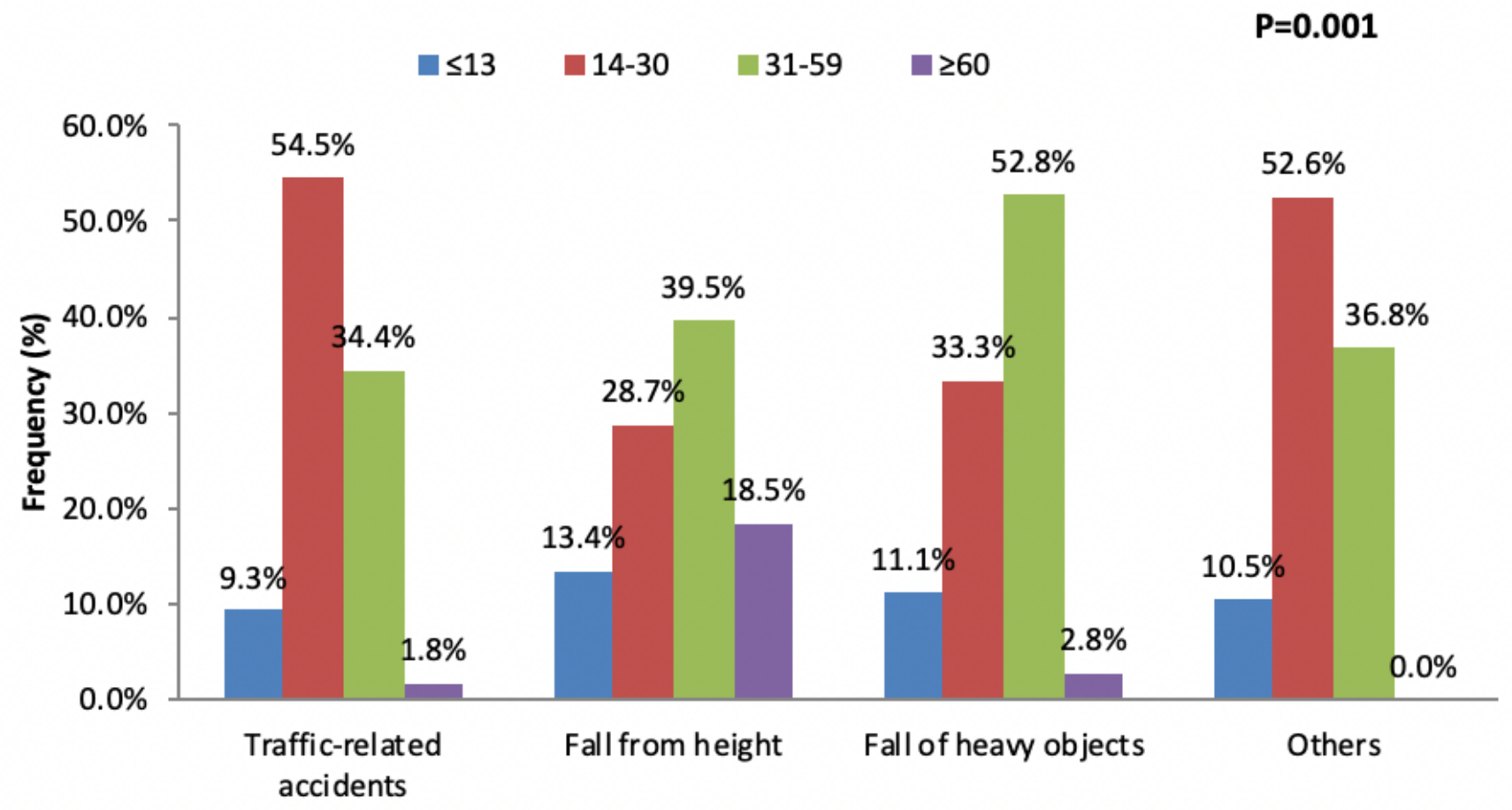

Figure 2

Mechanism of injury by age

\section{Supplementary Files}

This is a list of supplementary files associated with this preprint. Click to download.

- STROBEchecklist.docx 